\title{
Torque-producing capacity is affected by moment arm in the human knee extensors
}

\author{
Miyuki Hori, Tadashi Suga* ${ }^{*}$, Masafumi Terada, Yuto Miyake, Akinori Nagano and Tadao Isaka
}

\begin{abstract}
Objective: The torque-producing capacity can be assessed as maximal isometric torque per muscle size. Nevertheless, the factors contributing to this capacity remain poorly understood. In general, the magnitude of joint torque production is determined not only by muscle size but also by joint moment arm (MA). Based on this background, we hypothesized that longer MA would be related to higher torque-producing capacity despite a given muscle size. To test this hypothesis, we examined the relationship between MA and toque-producing capacity in the knee extensors. The quadriceps femoris muscle volume (MV) and knee extensor MA in 30 healthy young men were measured using magnetic resonance imaging. The knee extensor isometric torque was measured using a dynamometer. The knee extensor torque-producing capacity was calculated as the knee extensor isometric torque per quadriceps femoris MV.

Results: The quadriceps femoris MV and knee extensor MA correlated significantly with the knee extensor isometric torque $\left(r=0.785\right.$ and 0.790 , respectively, both $\left.P_{S}<0.001\right)$. Furthermore, the knee extensor MA correlated significantly with the knee extensor torque-producing capacity $(r=0.635, P<0.001)$. These findings suggest that longer MA is an important factor for achieving higher torque-producing capacity in the human knee extensors.
\end{abstract}

Keywords: Isometric torque, Muscle volume, Knee extension, Quadriceps femoris, Magnetic resonance imaging

\section{Introduction}

Maximal isometric torque per agonist muscle size is considered as the torque-producing capacity [1], which is also called specific strength or muscle quality [2-5]. This capacity is often associated with several factors, including physiological and neurological factors [3, 4, 6-8]. Previous studies demonstrated that toque-producing capacity was higher in younger subjects than in older subjects [3, $7,8]$. By contrast, other studies reported that torque-producing capacity was comparable between younger and older subjects [2, 9-11]. Additionally, Fukunaga et al. [11] reported that toque-producing capacity did not differ between trained and untrained subjects. They indicated that when several morphological factors such as the joint moment arm (MA), fascicle length, and pennation angle

*Correspondence: t-suga@fc.ritsumei.ac.jp

Faculty of Sport and Health Science, Ritsumeikan University, 1-1-1

Nojihigashi, Kusatsu, Shiga 525-8577, Japan were identical, torque-producing capacity remained unchanged.

The magnitude of joint torque is morphologically defined as the product of agonist muscle size and joint MA dimension. Previous studies demonstrated that a positive correlation between MA and isometric torque in several joints [12-14]. Blazevich et al. [13] determined that although knee extensor MA correlated with knee extensor isometric torque, the knee extensor MA ranged from 33.2 to $47.2 \mathrm{~mm}$. Baxter and Piazza [12] reported that although plantar flexor MA correlated with plantar flexor isometric torque, a difference between the subjects having the shortest and longest plantar flexor MAs was about $20 \mathrm{~mm}$. These findings suggest that the joint MA dimension is different among subjects in a single population. Thus, despite a given muscle size, subjects having a greater MA can be more enhanced torque-producing capacity than subjects having a smaller MA. Based on these backgrounds, we hypothesized that longer MA would be related to higher torque-generating capacity

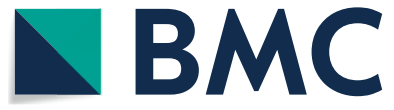

(c) The Author(s) 2020. This article is licensed under a Creative Commons Attribution 4.0 International License, which permits use, sharing, adaptation, distribution and reproduction in any medium or format, as long as you give appropriate credit to the original author(s) and the source, provide a link to the Creative Commons licence, and indicate if changes were made. The images or other third party material in this article are included in the article's Creative Commons licence, unless indicated otherwise in a credit line to the material. If material is not included in the article's Creative Commons licence and your intended use is not permitted by statutory regulation or exceeds the permitted use, you will need to obtain permission directly from the copyright holder. To view a copy of this licence, visit http://creativecommons.org/licenses/by/4.0/. The Creative Commons Public Domain Dedication waiver (http://creativecommons.org/publicdomain/zero/1.0/) applies to the data made available in this article, unless otherwise stated in a credit line to the data. 
among a single population. To test this hypothesis, the present study examined the relationship between MA and torque-generating capacity of the knee extensors in healthy adults.

\section{Main text \\ Methods \\ Subjects}

Thirty healthy young men (age: $21.9 \pm 1.8$ years, body height: $171.6 \pm 5.4 \mathrm{~cm}$, body weight: $66.0 \pm 7.9 \mathrm{~kg}$ ) participated in this study. The subjects were recreationally active but were not involved in any specific physical training program within the previous 3 years. Nevertheless, many of them had participated in recreational sports and/or physical training for $2-3 \mathrm{~h}$ per week. Informed written consent was obtained from all subjects. All subjects had no history of orthopedic injuries or previous surgery of the knee extensors, and were free of any known neurologic, cardiovascular, or pulmonary disorders. This study was approved by the Ethics Committee of Ritsumeikan University.

\section{Quadriceps femoris muscle volume (MV) and knee extensor MA}

Representative images of the mid-tight quadriceps femoris cross-sectional area (CSA) and knee extensor MA on magnetic resonance imaging (MRI) are shown in Fig. 1. The methods of MRI measurements of both axial and sagittal images for circulating the quadriceps femoris size and knee extensor MA of the right leg have been previously described $[15,16]$. The quadriceps femoris MV was calculated by multiplying the sum of the CSAs along their length at intervals of $10 \mathrm{~mm}$. The knee extensor MA was calculated as the distance between the tibio-femoral contact point and the mid-line of the patellar tendon $[13,15,16]$. The analyses for measuring the quadriceps femoris MV and knee extensor MA were conducted using image analysis software (OsiriX Version 5.6, Switzerland).

\section{Knee extensor isometric torque and torque-producing capacity}

The knee extensor isometric torque of the right leg was measured using a dynamometer (BIODEX system 3; BIODEX Medical, Shirley, NY, USA). Subjects were secured at the hip by a seat belt to prevent any movement of the hip joint. The hip and knee joint angles were fixed at $100^{\circ}$ and $90^{\circ}$ (full extension was at $180^{\circ}$ ), respectively. The ankle joint was attached to a bar connected to the force transducer. A $90^{\circ}$ of the knee angle during isometric contraction was selected as commonly adopted in previous studies $[8,13,14,17,18]$. The two trials for measuring isometric torque were each performed for $3 \mathrm{~s}$ with a $1-m$ rest period. If the difference between the torque values of the two trials was more than $5 \%$ of the highest value, additional trials were performed until this was corrected [18]. The highest value of the two trials, or more than two trials, was used as the knee extensor isometric torque. The knee extensor torque-generating capacity
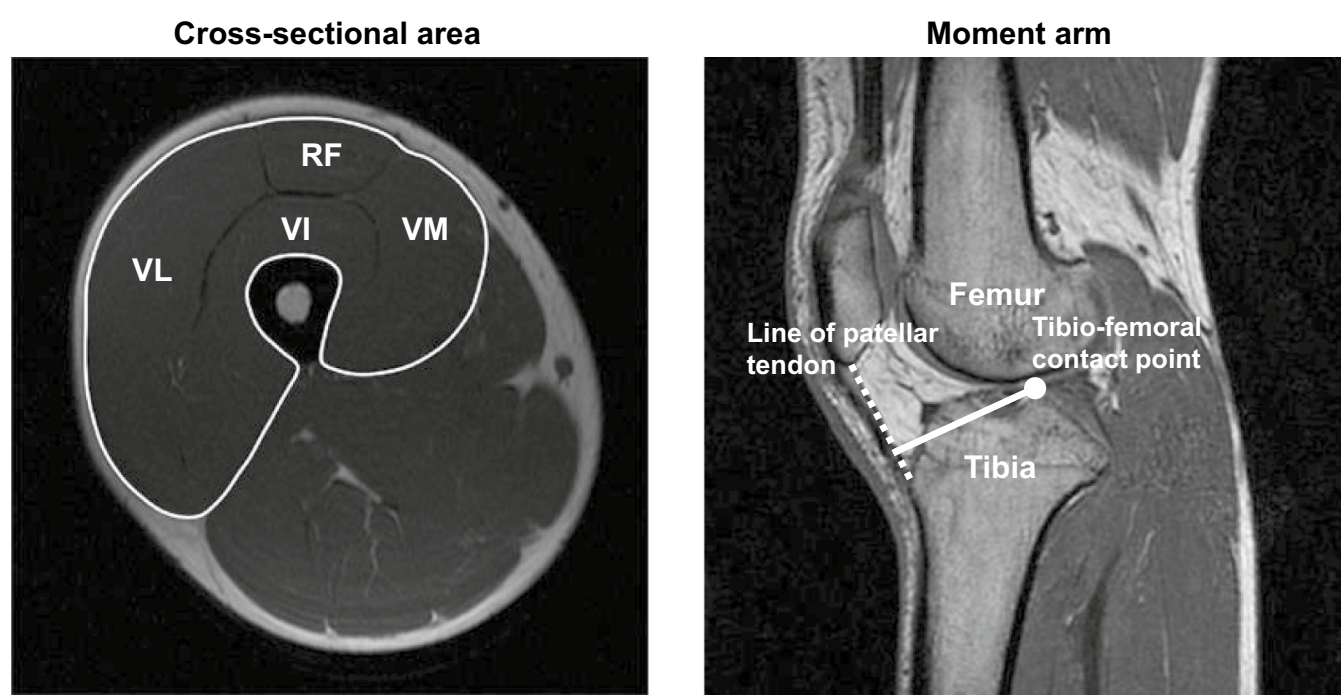

Fig. 1 Representative magnetic resonance imaging scans of mid-thigh quadriceps femoris cross-sectional area and knee extensor moment arm. The quadriceps femoris cross-sectional area included the rectus femoris (RF), vastus intermedius (VI), vastus lateralis (VL), and vastus medialis (VM). The quadriceps femoris muscle volume was calculated by multiplying the sum of the cross-sectional areas along their length at intervals of $10 \mathrm{~mm}$. The knee extensor moment arm was calculated as the distance between the tibio-femoral contact point and the mid-line of the patellar tendon 
was calculated as the knee extensor isometric torque per quadriceps femoris MV.

\section{Statistical analysis}

The data are presented as the mean \pm SD. Relationships between variables were evaluated using a Pearson's product moment correlation. To adjust for confounding factors, relationships between morphological parameters (i.e., the quadriceps femoris MV and knee extensor MA) and isometric torque of the knee extensors were examined using partial correlation analyses after controlling for body size. This model was adjusted for both body height and body weight. The level of statistical significance was defined at $P<0.05$. All statistical analyses were conducted using SPSS software (version 19.0; IBM Corp, Armonk, NY, USA).

\section{Results}

Mean values of measured variable in subjects were $2015.4 \pm 288.5$ (range, 1453.0 to 2488.2 ) $\mathrm{cm}^{3}$ for the quadriceps femoris $\mathrm{MV}, 43.8 \pm 2.4$ (range, $40.0 \pm 48.8$ ) $\mathrm{mm}$ for the knee extensor MA, $244.8 \pm 49.8$ (range, 158.6 to 357.5$) \mathrm{Nm}$ for the knee extensor isometric torque, and $0.121 \pm 0.015$ (range, 0.099 to 0.156 ) $\mathrm{Nm} / \mathrm{cm}^{2}$ for the knee extensor torque producing capacity.

Body height correlated significantly with the quadriceps femoris MV and knee extensor MA $(r=0.420$ and 0.456 , respectively, both $P_{\mathrm{s}}<0.05$ ). Body weight also correlated significantly with the quadriceps femoris $\mathrm{MV}$ and knee extensor MA ( $r=0.567$ and 0.456 , respectively, both $\left.P_{\mathrm{s}}<0.05\right)$. Additionally, there was a significant correlation between the quadriceps femoris MV and knee extensor MA $(r=0.577, P=0.001)$.
Relationships of the quadriceps femoris MV and knee extensor moment arm with knee extensor isometric toque are presented in Fig. 2. The quadriceps femoris MV correlated significantly with knee extensor isometric torque $(r=0.785, P<0.001)$. The knee extensor MA also correlated significantly with knee extensor isometric torque $(r=0.790, P<0.001)$. After adjusting for both body height and body weight, correlations of the quadriceps femoris MV and knee extensor MA with knee extensor isometric torque remained significant (partial $r=0.661$ and 0.700 , respectively, both $P_{\mathrm{s}}<0.001$ ).

Relationship between the knee extensor moment arm and torque-producing capacity is presented in Fig. 3. The knee extensor MA correlated significantly with knee extensor torque-producing capacity $(r=0.635, P<0.001)$.

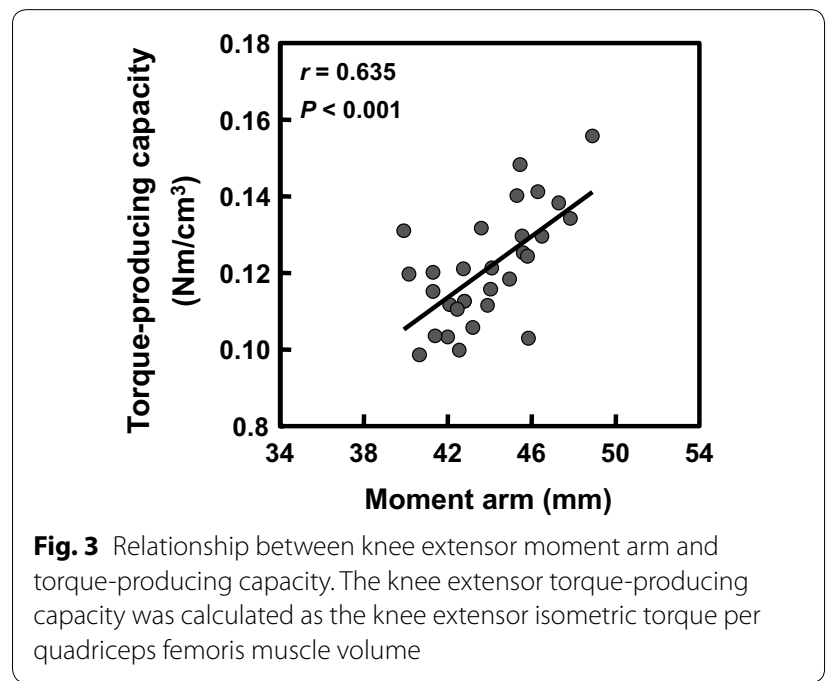

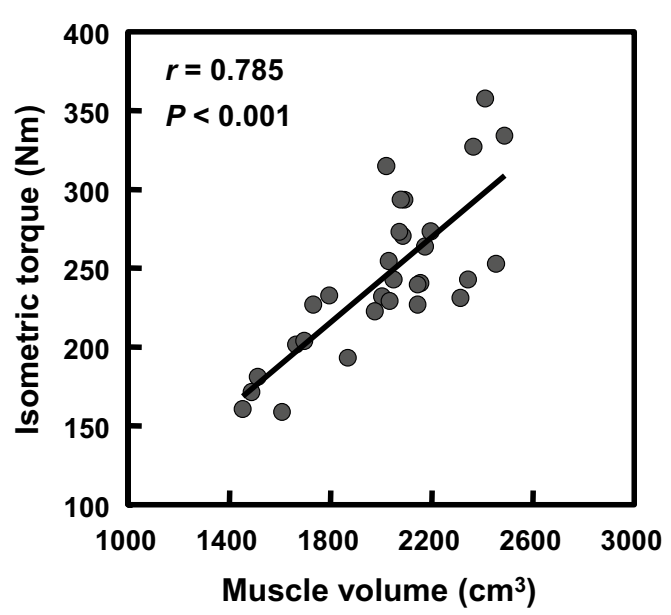

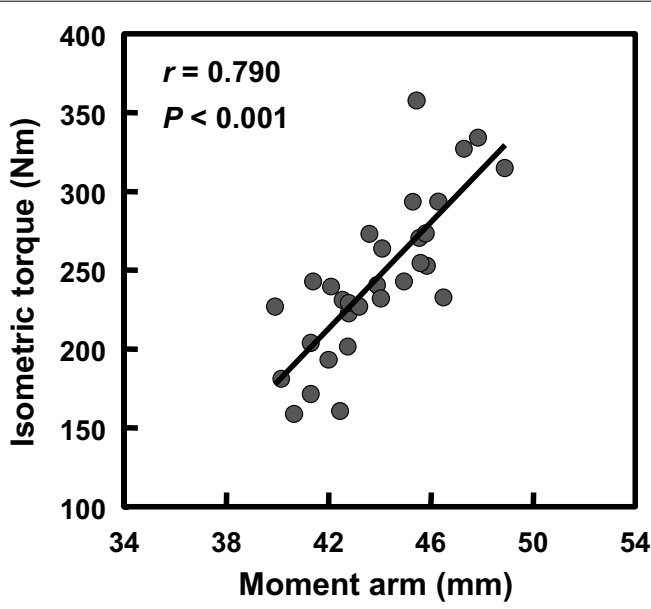

Fig. 2 Relationships of the quadriceps femoris muscle volume (right) and knee extensor moment arm (left) with knee extensor isometric toque 


\section{Discussion}

This study demonstrated a positive relationship between MA and isometric torque in the knee extensors; thus, this finding corroborates the results of the previous studies [12-14]. Moreover, we determined that after adjusting for body size, such a relationship remained significant, suggesting that the relationship between MA and isometric torque may be independent of the differences in body size among subjects. Furthermore, we found that longer knee extensor MA correlated with higher knee extensor torque-producing capacity. To the best of our knowledge, the present study is the first to examine the relationship between MA and torque-producing capacity and to indicate that torque-producing capacity is affected by MA.

Previous studies determined that torque-producing capacity was higher in younger subjects than in older subjects [3, 7, 8]. Macalusoa et al. [8] reported that torque-producing capacity of the knee extensors was higher in younger subjects than in older subjects. By contrast, a series of studies by Akagi et al. $[9,10]$ reported that torque-producing capacity of the elbow flexors and extensors were comparable between younger and older subjects. Additionally, Fukunaga et al. [11] reported that the torque-producing capacity of the elbow flexors and extensors did not differ between trained and untrained subjects. Therefore, there is a discrepancy in the previous findings regarding the presence or absence of the difference in torque-producing capacity among several populations. This discrepancy may be attributed to the differences among joints (e.g., elbow vs. knee joints) employed in these previous studies.

In addition to this possibility, Sugisaki et al. [19] examined the difference in the elbow extensor MAs among some elbow extension angles and reported that the mean value of the longest elbow extensor MA among these joint angles in the subjects was $23.9 \pm 1.5 \mathrm{~mm}$. This dimension of the elbow extensor MA is nearly 1.8-fold shorter than that of the knee extensor MA $(43.8 \pm 2.4 \mathrm{~mm})$ measured in the present study. Furthermore, in a study by Sugisaki et al. [19], they reported that the difference between subjects having the shortest and longest elbow extensor MAs was about $4 \mathrm{~mm}$. In the present study, we determined that the difference between subjects having the shortest and longest knee extensor MAs was about $9 \mathrm{~mm}$. Blazevich et al. [13] reported that the difference between subjects having the shortest and longest knee extensor MAs was about $14 \mathrm{~mm}$. In association with the difference in the knee extensor MA among subjects, we found that the difference between subjects having the lowest and highest knee extensor torque-producing capacities was nearly 1.6-fold. Considering these findings, the differences in absolute MA dimension and/ or its related joint structure between the elbow and knee joints may be associated with the degree of the difference in torque-producing capacity among several populations. Therefore, we suggest that individuality (i.e., dimension and structure) of the joint among subjects may affect the magnitude of torque-producing capacity of the knee extensors.

The MV is more associated with joint torque than other muscle size parameters such as muscle thickness and anatomical CSA [11]. Additionally, the MV includes components of pennation angle and fascicle length [9, 10]. Nevertheless, the pennation angle and fascicle length may be useful in clearly understanding the present findings; however, the present study did not measure these morphological parameters. Previous studies determined that greater pennation angles of individual muscles among the quadriceps femoris correlated with higher knee extensor isometric torque in healthy adults $[14,17]$. Furthermore, previous studies reported a potential relationship between longer fascicle length and higher joint torque $[20,21]$. However, whether the magnitudes of pennation angle and fascicle length would be related to torque-producing capacity remains unclear.

Trezise et al. [14] reported that the knee extensor isometric torque correlated with electromyographic activity of individuals muscles among the quadriceps femoris during isometric contraction. Furthermore, previous studies determined that torque-producing capacity may be affected by neuromuscular factors [3, 4, 6-8]. In addition, previous studies reported a potential relationship between torque-producing capacity and muscle fiber composition [22, 23]. To clarify the impact of MA on torque-producing capacity, further studies are needed to examine the individual and interaction effects of morphological, neuromuscular, and physiological factors on torque-producing capacity.

In conclusion, this study demonstrated a positive relationship between MA and torque-producing capacity of the knee extensors in young adults. The present study it the first to determine that longer MA is an important morphological factor for achieving higher torque-producing capacity. In recent studies, we determined that longer knee extensor MA was related to higher sprint performance in sprinters $[15,16]$, whereas no such a relationship was found with the quadriceps femoris size. Based on the present findings, we hypothesize that sprinters having a longer knee extensor MA can achieve higher sprint performance than sprinters having a shorter knee extensor MA, potentially by enhancing torqueproducing capacity, despite a given quadriceps femoris size. To test our hypothesis, further studies are needed to determine the relationships of the knee extensor MA and torque-producing capacity with sprint performance in sprinters. 


\section{Limitation}

This study measured the knee extensor MA with both knees fully extended because of a technical limitation of our MRI measurement, as in our and other previous studies $[13,15,16]$. Thus, the joint angle (i.e., $180^{\circ}$ ) of the knee extensor MA is different from that during isometric contraction (i.e., 90). Nevertheless, previous studies have indicated that the difference in the knee extensor MA at full knee extension (i.e., $180^{\circ}$ ) among subjects is remained at a joint angle of $90^{\circ}[24,25]$. Therefore, the present finding can be considered reasonable.

\section{Abbreviations}

CSA: Cross-sectional area; MA: Moment arm; MRI: Magnetic resonance imaging; MV: Muscle volume.

\section{Acknowledgements}

We are grateful to all subjects who gave of their time and effort to participate in this study.

\section{Authors' contributions}

$\mathrm{MH}$ and TS conceived and designed the experiment; MH TS, MT and YM performed experiments; MH and TS analyzed data; MH, TS, MT, YM, AN and TI interpreted results of experiments; MH and TS wrote the manuscript; MT, AN and TI edited and revised manuscript. All authors read and approved the manuscript.

\section{Funding}

There were no specific grants or funding for the present study.

\section{Availability of data and materials}

Data will be provided the corresponding author upon request.

\section{Ethics approval and consent to participate}

This study was approved by the Ethics Committee of Ritsumeikan University (BKC-IRB-2016-047). Informed written consent was obtained from all participants.

\section{Consent for publication}

Not applicable.

\section{Competing interests}

The authors declare that they have no competing interests.

Received: 16 April 2020 Accepted: 14 July 2020

Published online: 20 July 2020

\section{References}

1. Lieber RL, Friden J. Functional and clinical significance of skeletal muscle architecture. Muscle Nerve. 2000;23(11):1647-66.

2. Kent-Braun JA, Ng AV. Specific strength and voluntary muscle activation in young and elderly women and men. J Appl Physiol. 1999;87(1):22-9.

3. Morse Cl, Thom JM, Reeves ND, Birch KM, Narici MV. In vivo physiological cross-sectional area and specific force are reduced in the gastrocnemius of elderly men. J Appl Physiol. 2005;99(3):1050-5.

4. Reeves ND, Narici MV, Maganaris CN. Effect of resistance training on skeletal muscle-specific force in elderly humans. J Appl Physiol. 2004;96(3):885-92.

5. Tracy BL, Ivey FM, Hurlbut D, Martel GF, Lemmer JT, Siegel EL, Metter EJ, Fozard JL, Fleg JL, Hurley BF. Muscle quality. II. Effects of strength training in 65- to 75-yr-old men and women. J Appl Physiol. 1999;86(1):195-201.
6. Alway SE, Coggan AR, Sproul MS, Abduljalil AM, Robitaille PM. Muscle torque in young and older untrained and endurance-trained men. J Gerontol A Biol Sci Med Sci. 1996;51(3):B195-201.

7. Klein CS, Rice CL, Marsh GD. Normalized force, activation, and coactivation in the arm muscles of young and old men. J Appl Physiol. 2001;91(3):1341-9.

8. Macaluso A, Nimmo MA, Foster JE, Cockburn M, McMillan NC, De Vito G. Contractile muscle volume and agonist-antagonist coactivation account for differences in torque between young and older women. Muscle Nerve. 2002;25(6):858-63.

9. Akagi R, Takai Y, Ohta M, Kanehisa H, Fukunaga T, Kawakami Y. Sizestrength relationships of the elbow flexors and extensors are not affected by age or gender. Eur J Sport Sci. 2011;11(4):277-82.

10. Akagi R, Takai Y, Ohta M, Kanehisa H, Kawakami Y, Fukunaga T. Muscle volume compared to cross-sectional area is more appropriate for evaluating muscle strength in young and elderly individuals. Age Ageing. 2009;38(5):564-9.

11. Fukunaga T, Miyatani M, Tachi M, Kouzaki M, Kawakami Y, Kanehisa H. Muscle volume is a major determinant of joint torque in humans. Acta Physiol Scand. 2001;172(4):249-55.

12. Baxter JR, Piazza SJ. Planter flexor moment arm and muscle volume predict torque-generating capacity in young men. J Appl Physiol. 2014;116(5):538-44.

13. Blazevich AJ, Coleman DR, Horne S, Cannavan D. Anatomical predictors of maximum isometric and concentric knee extensor moment. Eur J Appl Physiol. 2009;105(6):869-78.

14. Trezise J, Collier N, Blazevich AJ. Anatomical and neuromuscular variables strongly predict maximum knee extension torque in healthy men. Eur J Appl Physiol. 2016;116(6):1159-77.

15. Miyake Y, Suga T, Otsuka M, Tanaka T, Misaki J, Kudo S, Nagano A, Isaka T. The knee extensor moment arm is associated with performance in male sprinters. Eur J Appl Physiol. 2017;117(3):533-9.

16. Tomita D, Suga T, Ueno H, Miyake Y, Otsuka M, Terada M, Nagano A, Isaka T. Relationship between knee extensor moment arm and long sprint performance in male 400-m sprinters. Transl Sports Med. 2018;1(4):172-9.

17. Ando R, Saito A, Umemura Y, Akima H. Local architecture of the vastus intermedius is a better predictor of knee extension force than that of the other quadriceps femoris muscle heads. Clin Physiol Funct Imaging 2015;35(5):376-82.

18. Tanaka D, Suga T, Tanaka T, Kido K, Honjo T, Fujita S, Hamaoka T, Isaka T. Ischemic preconditioning enhances muscle endurance during sustained isometric exercise. Int J Sports Med. 2016;37(8):614-8.

19. Sugisaki N, Wakahara T, Miyamoto N, Murata K, Kanehisa H, Kawakami Y, Fukunaga T. Influence of muscle anatomical cross-sectional area on the moment arm length of the triceps brachii muscle at the elbow joint. J Biomech. 2010;43(14):2844-7.

20. Drazan JF, Hullfish TJ, Baxter JR. Muscle structure governs joint function: linking natural variation in medial gastrocnemius structure with isokinetic plantar flexor function. Biol Open. 2019;8(12):bio048520.

21. Kumagai K, Abe T, Brechue WF, Ryushi T, Takano S, Mizuno M. Sprint performance is related to muscle fascicle length in male 100-m sprinters. J Appl Physiol. 2000;88(3):811-6.

22. Bottinelli R, Canepari M, Pellegrino MA, Reggiani C. Force-velocity properties of human skeletal muscle fibres: myosin heavy chain isoform and temperature dependence. J Physiol. 1996;495(2):573-86.

23. Larsson $L$, Moss RL. Maximum velocity of shortening in relation to myosin isoform composition in single fibres from human skeletal muscles. J Physiol. 1993;472:595-614.

24. Krevolin JL, Pandy MG, Pearce JC. Moment arm of the patellar tendon in the human knee. J Biomech. 2004;37(5):785-8.

25. Tsaopoulos DE, Baltzopoulos V, Maganaris CN. Human patellar tendon moment arm length: measurement considerations and clinical implications for joint loading assessment. Clin Biomech. 2006;21(7):657-67.

\section{Publisher's Note}

Springer Nature remains neutral with regard to jurisdictional claims in published maps and institutional affiliations. 